\title{
Changing paradigms for the treatment of brain metastasis
}

\author{
Jason Sheehan, M.D., Ph.D., ${ }^{1}$ AND Jonas Sheehan, M.D. ${ }^{2}$ \\ ${ }^{1}$ Department of Neurosurgery, University of Virginia Health System, Charlottesville, Virginia; \\ and ${ }^{2}$ Department of Neurosurgery, Milton S. Hershey Medical Center College of Medicine, \\ Hershey, Pennsylvania
}

$\mathrm{B}$ RAIN METASTASIS is the single most common type of intracranial tumor. ${ }^{9}$ Each year, the number of newly diagnosed brain lesions exceeds the total number of other intracranial tumors. In the US alone, more than 100,000 people suffer brain metastases each year. The incidence continues to increase as advances are made in the treatment of systemic cancer. Further complicating the clinical picture is the fact that many patients will present with multiple lesions and have a high chance of harboring additional tumors the longer they live. . $^{47,9}$

Despite the staggering clinical problem, brain metastasis historically has been an orphan disease. Medical oncologists had little to offer, given that chemotherapy generally does not penetrate the blood-brain barrier. Typically, neurosurgeons would operate only in patients with solitary, accessible, symptomatic tumors and low perioperative risks usually indicating limited systemic disease. Radiation oncologists could perform whole-brain radiation therapy (WBRT) but had little else to offer should the disease continue to progress or new lesions develop.

In the past decade, a significant shift has occurred in the treatment paradigm of brain metastasis. The Radiation Therapy Oncology Group (RTOG) 9508 demonstrated that radiosurgery in combination with WBRT leads to an improvement in the quality of life and local tumor control in patients with one to three brain metastases. ${ }^{1}$ In addition, RTOG 9508 revealed improved survival in patients with a solitary metastasis who receive radiosurgery plus WBRT rather than WBRT alone. Data from many other studies have shown the significant benefits of radiosurgery for brain metastasis and suggest that number of metastases is not the limiting factor in terms of a successful outcome. ${ }^{2,3,8,10}$ Longer survival, improved disease control, better quality of life, and improved neurocognitive function for patients with brain metastasis is becoming the norm.

With an expanding treatment armamentarium including extirpation, local chemotherapy, and radiosurgery, neurosurgeons are much more involved in the care of patients with brain metastasis. Now, large series of patients with brain metastasis are demonstrating that survival is limited not by intracranial but by extracranial disease progression. Neurosurgeons have pushed the onus of prolonging survival in patients with brain metastases back to the oncolo- gists. The treatment of patients with brain metastasis will continue to require multimodal therapy including chemotherapy, biological agents, WBRT, resection, and radiosurgery; thus, a multidisciplinary team will be required to manage intracranial and extracranial disease aggressively. This issue of Neurosurgical Focus represents an overview of current treatment modalities for brain metastases, and reports are drawn from a broad range of physicians.

\section{References}

1. Andrews DW, Scott CB, Sperduto PW, Flanders AE, Gaspar LI, Schell MC, et al: Whole brain radiation therapy with or without stereotactic radiosurgery boost for patients with one to three brain metastases: Phase III results of the RTOG 9508 randomised trial. Lancet 363:1665-1672, 2004

2. Aoyama H, Shirato H, Tago M, Nakagawa K, Toyoda T, Hatano K, et al: Stereotactic radiosurgery plus whole-brain radiation therapy vs stereotactic radiosurgery alone for treatment of brain metastases: a randomized controlled trial. JAMA 295: 2483-2491, 2006

3. Bhatnagar A, Flickinger J, Kondziolka D, Lunsford LD: Stereotactic radiosurgery for four or more intracranial metastases. Int J Radiat Oncol Biol Phys 64:898-903, 2006

4. Chason JL, Walker FB, Landers JW: Metastatic carcinoma in the central nervous system and dorsal root ganglia. A prospective autopsy study. Cancer 16:781-787, 1963

5. Decker DA, Decker VL, Herskovic A, Cummings GD: Brain metastases in patients with renal cell carcinoma: prognosis and treatment. J Clin Oncol 2:169-173, 1984

6. Delattre JY, Krol G, Thaler HT, Posner JB: Distribution of brain metastases. Arch Neurol 45:741-744, 1988

7. Galluzzi S, Payne D: Brain metastases from primary bronchial carcinoma: a statistical study of 741 necropsies. Br J Cancer 10:408-414, 1956

8. Noel G, Bollet MA, Noel S, Feuvret L, Boisserie G, Tep B, et al: Linac stereotactic radiosurgery: an effective and safe treatment for elderly patients with brain metastases. Int J Radiat Oncol Biol Phys 63:1555-1561, 2005

9. Sawaya R, Bindal RK: Metastatic brain tumors, in Kaye AH, Laws E (eds): Brain Tumors: An Encyclopedic Approach. Edinburgh: Churchill Livingstone, 1995, pp 923-946

10. Sheehan JP, Sun MH, Kondziolka D, Flickinger J, Lunsford LD: Radiosurgery for non-small cell lung carcinoma metastatic to the brain: long-term outcomes and prognostic factors influencing patient survival time and local tumor control. J Neurosurg 97:1276-1281, 2002 